\title{
A dry origin of 4-Vesta estimated by the water content in pyroxenes from the HED
}

\author{
S. NaZZareni ${ }^{1 *}$, C. Pauselli ${ }^{1}$, H. Skogby ${ }^{2}$, M.

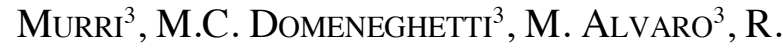 \\ StAlder $^{4}$, M. Petrelli ${ }^{1}$, M.C. De Sanctis ${ }^{5}$, M. \\ FORMISANO $^{5}$ AND C. FEDERICO ${ }^{5}$ \\ ${ }^{1}$ University of Perugia, Perugia, I-06123, Italy (*correspondence: \\ sabrina.nazzareni@unipg.it ) \\ ${ }^{2}$ Swedish Museum of Natural History, Stockholm, Sweden \\ ${ }^{3}$ University of Pavia, Pavia, Italy \\ ${ }^{4}$ University of Innsbruck, Innsbruck, Austria \\ ${ }^{5}$ INAF, Roma, Italy
}

The HED meteorites provide a uniquely detailed record of differentiation processes that occurred on the early-formed basaltic 4-Vesta asteroid. We used pyroxenes from eucrites (Juvinas, Serra de Magè, Stannern), howardite (Luotolax, Kapoeta) and one diogenite (Shalka) as proxy to estimate the water content of 4Vesta. Pigeonite and orthopyroxene were extracted from the HED meteorites and measured by FTIR spectroscopy in the region $6000-2000 \mathrm{~cm}^{-1}$. The integrated area of $\mathrm{OH}$ bands is used to estimate the water content of pyroxene and then to calculate the primitive magma water content. However, no specific opx $\mathrm{OH}$ bands could be observed.

Since $\mathrm{H}$ diffusion coupled to redox exchange with $\mathrm{Fe}$ is very fast $\left(10-13 \mathrm{~cm}^{2} / \mathrm{sec}\right.$ at $\left.1100^{\circ} \mathrm{C}\right)$ in pyroxene, hydrogen can be lost during late stage(s) of magmatic evolution. In pyroxene $\mathrm{H}$ is incorporated associated to point defects that are retained in the structure during the $\mathrm{H}$ loss processes. By experimentally reversing the redox reaction under reducing conditions at $700-800^{\circ} \mathrm{C}$, the original $\mathrm{H}$ content of pyroxene can be recovered.

After FTIR measurements on untreated HED pyroxenes, we performed several annealing experiments under hydrogen atmosphere at $1 \mathrm{Atm}$ and $700-800^{\circ} \mathrm{C}$ and hydrothermal experiments at $0.2 \mathrm{GPa}$ and $700^{\circ} \mathrm{C}$ to assess the $\mathrm{H}$ uptake that corresponds to previous $\mathrm{H}$ loss. FTIR spectra were recorded after each heating step but none of the HED pyroxenes showed $\mathrm{OH}$ band signal (detection limit is 4-5 $\mathrm{ppm} \mathrm{H}_{2} \mathrm{O}$ ).

We thus conclude that the "dry" condition of 4-Vesta magmas is primary and that no $\mathrm{H}$ loss occurred in pyroxene during the evolution of the asteroid.

Acknowledgements

MM, MA and MCD were supported by the IMPACt project (R164WEJAHH) to MA 